\title{
A multivariable Mendelian randomization analysis disentangling the causal relations between abdominal obesity, non-alcoholic fatty liver disease and cardiometabolic diseases
}

\author{
Running title: Obesity, fatty liver and cardiometabolic diseases
}

William Pelletier, BSc ${ }^{1}$, Éloi Gagnon, $\mathrm{MSc}^{1} *$, Émilie Gobeil, $\mathrm{BSc}^{1}$, Jérôme Bourgault, $\mathrm{MSc}^{1}$, Hasanga D. Manikpurage, $\mathrm{MSc}^{1}$, Ina Maltais-Payette, $\mathrm{MSc}^{1,2}$, Erik Abner, $\mathrm{PhD}^{3}$, Nele Taba, $\mathrm{MSc}^{3,4}$, Tõnu Esko, $\mathrm{PhD}^{3}$, Patricia L. Mitchell, $\mathrm{PhD}^{1}$, Nooshin Ghodsian, $\mathrm{PhD}^{1}$, Jean-Pierre Després, $\mathrm{PhD}^{5}$, Marie-Claude Vohl, $\mathrm{PhD}^{2,6}$, André Tchernof, $\mathrm{PhD}^{1,2}$, Sébastien Thériault, $\mathrm{MD}, \mathrm{MSc}^{1,7}$, and Benoit J.Arsenault, $\mathrm{PhD}^{1,8 * *}$

1) Centre de recherche de l'Institut universitaire de cardiologie et de pneumologie de Québec, Québec (QC), Canada

2) School of Nutrition, Université Laval, Québec (QC), Canada

3) Estonian Genome Center, Institute of Genomics, University of Tartu, Tartu, Riia 23b, 51010, Estonia

4) Institute of Molecular and Cell Biology, University of Tartu, Tartu, Riia 23, 51,010, Estonia

5) VITAM - Centre de recherche en santé durable, Université Laval

6) Centre NUTRISS, Institut sur la nutrition et les aliments fonctionnels, Université Laval, Québec (QC), Canada.

7) Department of Molecular Biology, Medical Biochemistry and Pathology, Faculty of Medicine, Université Laval, Québec (QC), Canada

8) Department of Medicine, Faculty of Medicine, Université Laval, Québec (QC), Canada

* These authors contributed equally to this manuscript

\section{**Address for correspondence}

Benoit Arsenault, $\mathrm{PhD}$

Centre de recherche de l'Institut universitaire de cardiologie et de pneumologie de Québec -Université Laval. Y-3106, Pavillon Marguerite D'Youville, 2725 chemin Ste-Foy Québec (QC), Canada G1V 4G5 Telephone: 418-656-8711 ext. 3498 - Email : benoit.arsenault@ criucpq.ulaval.ca 
medRxiv preprint doi: https://doi.org/10.1101/2021.09.28.21264201; this version posted September 29, 2021. The copyright holder for this preprint (which was not certified by peer review) is the author/funder, who has granted medRxiv a license to display the preprint in perpetuity.

\begin{abstract}
Background: Observational studies have linked obesity and especially abdominal obesity to nonalcoholic fatty liver disease (NAFLD). These traits are also associated with type 2 diabetes (T2D) and coronary artery disease (CAD) but the causal factor(s) underlying these associations remain unexplored.
\end{abstract}

Methods: We used a multivariable Mendelian randomization (MVMR) study design to determine whether obesity (defined using body mass index [BMI]) and abdominal obesity (defined using waist circumference) were causally associated with NAFLD using publicly available genome-wide association study (GWAS) summary statistics of the UK Biobank $(n>450,000)$ and a GWAS meta-analysis of NAFLD (8434 cases and 770,180 control). A MVMR study design was also used to determine the respective causal contributions of waist circumference and NAFLD to T2D and CAD using additional GWAS summary statistics of the DIAGRAM (74,124 cases and 824,006 controls) and CARDIoGRAMplusC4D (122,733 cases and 424,528 controls) consortia.

Results: In univariable Mendelian randomization analyses, both BMI and waist circumference were associated with NAFLD. NAFLD was not associated with obesity or abdominal obesity. In MVMR analyses, waist circumference was associated with NAFLD when accounting for BMI (OR per 1standard deviation increase $=2.5695 \% \mathrm{CI}: 1.39-4.69, \mathrm{p}=2.4 \mathrm{e}-03$ ) and BMI was not associated with NAFLD when accounting for waist circumference $(0.8195 \% \mathrm{CI}: 0.5-1.31, \mathrm{p}=3.9 \mathrm{e}-01)$. In MVMR analyses accounting for NAFLD, waist circumference remained strongly associated with both T2D (3.25 95\% CI: 2.87-3.68, p=5.1e-77) and CAD (1.62 95\% CI: 1.48-1.76, p=6.5e-28).

Conclusions: These results identified abdominal obesity as a strong, independent and causal contributor to NAFLD, T2D and CAD, suggesting that interventions targeting abdominal obesity rather than body weight per se should be prioritized for the prevention and management of cardiometabolic diseases.

Keywords: Abdominal obesity, Non-alcoholic fatty liver disease, Type 2 diabetes, Coronary artery disease, Mendelian randomization 
medRxiv preprint doi: https://doi.org/10.1101/2021.09.28.21264201; this version posted September 29, 2021. The copyright holder for this

preprint (which was not certified by peer review) is the author/funder, who has granted medRxiv a license to display the preprint in perpetuity.

Pelletier et al.

It is made available under a CC-BY 4.0 International license .

Page 3

\section{Introduction}

Non-alcoholic fatty liver disease (NAFLD) is characterized by hepatic lipid accumulation ranging from simple steatosis (>5\% of liver weight is lipids) to non-alcoholic steatohepatitis (NASH, presence of inflammation) (Chalasani et al., 2018). Although simple steatosis is relatively benign, more severe forms of NAFLD such as NASH and hepatic fibrosis can lead to liver cirrhosis and hepatocellular carcinoma. Approximately $25 \%$ of the adult population globally is affected by NAFLD with the prevalence rapidly increasing and potentially becoming the leading cause of liver failure in the United States by 2025 (Charlton et al., 2011; Younossi et al., 2016). Obesity and body fat distribution are closely linked with NAFLD (Ross et al., 2020). In the INSPIRE ME study, a large international imaging study by computed tomography, waist circumference was closely associated with liver fat accumulation independently of body mass index (BMI) (Nazare et al., 2015).

Studies have also shown that both liver fat accumulation/NAFLD and waist circumference are associated with CAD and T2D (Fabbrini et al., 2009; Kotronen \& Yki-Järvinen, 2008; Ndumele et al., 2011; Tilg, Moschen, \& Roden, 2017). However, whether or not these relationships are causal remains to be elucidated and, more importantly, whether or not agents aimed at targeting NAFLD will ultimately decrease the risk of either T2D or CAD is unknown. In a previous investigation, we showed a strong genetic correlation between NAFLD, waist circumference, T2D and CAD (Ghodsian, 2021). However, little is known about the directionality of these relationships and whether NAFLD lies in the causal pathway linking abdominal obesity and T2D/CAD.

In order to gain insight about the causality and directionality of these associations, new causal inference methods such as Mendelian randomization (MR) have been developed. MR uses genetic variants (which are randomly distributed at meiosis) such as single-nucleotide polymorphisms (SNPs), as instruments to infer causality. This method is comparable to a randomized control trial in which participants are naturally randomized based on the presence or absence of genetic variants that influence traits of interest. In a previous MR study, waist-to-hip ratio (WHR) adjusted for BMI was strongly associated with T2D and CAD (Emdin et al., 2017). However, we do not know if similar associations exist for NAFLD. 
medRxiv preprint doi: https://doi.org/10.1101/2021.09.28.21264201; this version posted September 29, 2021. The copyright holder for this

preprint (which was not certified by peer review) is the author/funder, who has granted medRxiv a license to display the preprint in perpetuity.

Pelletier et al.

It is made available under a CC-BY 4.0 International license.

Extensions of the MR design, such as bidirectional MR and multivariable MR (MVMR), help in clarifying causal relations. Bidirectional MR refers to an analysis where both traits are alternately evaluated as exposure and outcome. This method has the potential to remove reverse causation bias by asserting the directionality of the relationship (Welsh et al., 2010). Multivariable MR is used when multiple genetic variants are associated to two or more exposures. It conditions the effects of the SNPs of each exposure together to assess the effect of each exposure independently on the outcome. This method allows the identification of the true causal factor when two exposures share genetic variants as if they had been adjusted for one another (Sanderson, Davey Smith, Windmeijer, \& Bowden, 2019).

Here, we first used bidirectional and multivariable MR designs to investigate the respective causal contributions of obesity (defined using BMI) and abdominal obesity (defined using waist circumference) to NAFLD. Second, using a similar strategy, we aimed to determine if abdominal obesity and NAFLD are independent causal risk factors for T2D and CAD.

\section{Results}

\section{Bi-directional associations between obesity and NAFLD}

The study design and cohorts used in this MR study are presented in Figure 1. We first investigated the bi-directional associations between obesity (defined by BMI or waist circumference) and NAFLD using Inverse Variance Weighted (IVW)-MR and other robust analyses described in the Methods section. Results from all MR methods (Figure 2) suggest that BMI and waist circumference are both causally associated with NAFLD, while NAFLD is not associated with obesity or abdominal obesity. A one standard deviation (SD)-higher waist circumference had an odds ratio (OR) of 2.03 (95\% confidence interval [CI]: 1.76-2.34, $\mathrm{p}=6.7 \mathrm{e}-23$ ) for NAFLD and a one SD-higher BMI had an OR of 1.67 (95 \% CI: 1.49-1.87, p=1.0e-18) (Figure 3). Specifically, every additional centimeter of waist circumference increased the risk of NAFLD (OR=1.05, CI: 1.04-1.07, $\mathrm{p}=6.7 \mathrm{e}-23$ ) and every BMI point increased the risk of NAFLD (OR=1.11, CI: 1.09-1.14, $\mathrm{p}=1.0 \mathrm{e}-18)$. When BMI and waist circumference were assessed together in MVMR, only waist circumference ( $\mathrm{OR}=2.56$ 95\% CI: 1.39 $4.69, \mathrm{p}=2.4 \mathrm{e}-03$ ) retained a robust association with NAFLD, while the effect of BMI was not significant $(\mathrm{OR}=0.81$ 95\% CI=0.50-1.31, $\mathrm{p}=3.9 \mathrm{e}-01)$ (Figure 3). Similar results were obtained using the 
medRxiv preprint doi: https://doi.org/10.1101/2021.09.28.21264201; this version posted September 29, 2021. The copyright holder for this

preprint (which was not certified by peer review) is the author/funder, who has granted medRxiv a license to display the preprint in perpetuity.

Pelletier et al.

It is made available under a CC-BY 4.0 International license .

Genetic Investigation of Anthropometric Traits (GIANT) consortium as study exposures for WC and BMI (Supplementary Figures 1-2).

We investigated the association of WHR adjusted for BMI with NAFLD using multiple MR methods. A higher genetically predicted WHR adjusted for BMI was associated with NAFLD across all MR methods (Figure 4). Altogether, these analyses provide evidence that body fat distribution patterns consistent with higher visceral fat accumulation is an important determinant of NAFLD, regardless of subcutaneous fat accumulation or obesity indices that do not take into account body composition such as the BMI.

Contributions of abdominal obesity and non-alcoholic fatty liver disease to type 2 diabetes and CAD In IVW-MR, a 1-SD increment in waist circumference or 1-log(OR) increment of NAFLD was associated with T2D $(\mathrm{OR}=3.6895 \% \mathrm{CI}: 3.29-4.13$, $\mathrm{p}=2.9 \mathrm{e}-110$ and $\mathrm{OR}=1.2495 \%$ CI: $1.05-1.47$, $\mathrm{p}=1.2 \mathrm{e}-02$, respectively for waist circumference and NAFLD) (Figure 5, left panel). NAFLD MR estimates on T2D were consistent for all MR methods and significant for most MR methods (Supplementary figure 3). When waist circumference and NAFLD were assessed together in MVMR, waist circumference $(\mathrm{OR}=3.25$ 95\% CI: 2.87-3.68, $\mathrm{p}=5.1 \mathrm{e}-77$ and NAFLD (1.19 95\% CI: 1.12-1.27, $\mathrm{p}=1.6 \mathrm{e}-07$ ) increased the risk of T2D. When deriving WC instruments from GIANT, NAFLD was not associated with T2D when accounting for WC in MVMR (OR=1.05 95\% CI: 0.72-1.53, p=8.0e-01) (Supplementary Figures 4 left panel). This inconsistency between study cohorts is likely a result of the minimal genetic coverage in GIANT. GIANT summary statistics only included one of the four genetic instruments of NAFLD or their LD proxy R2 $>0.8$.

In IVW-MR, a 1-SD increment in waist circumference was associated with CAD (OR=1.62 95\% CI: 1.50-1.74, p=2.9e-37), while NALFD was not associated with CAD (Figure 5, right panel). When waist circumference and NAFLD were assessed together in MVMR, waist circumference retained a robust association with CAD (OR=1.62 95\% CI: 1.48-1.76, $\mathrm{p}=6.5 \mathrm{e}-28)$ while NAFLD was not associated with CAD. The results were similar when deriving WC instruments from GIANT (Supplementary Figure 4 right panel). Results of this analysis revealed that abdominal obesity is a stronger risk factor for T2D and CAD than NAFLD. Although abdominal obesity is closely associated with NAFLD, the impact of abdominal obesity on T2D and CAD is minimally mediated by NAFLD. 
medRxiv preprint doi: https://doi.org/10.1101/2021.09.28.21264201; this version posted September 29, 2021. The copyright holder for this preprint (which was not certified by peer review) is the author/funder, who has granted medRxiv a license to display the preprint in perpetuity.

\section{Discussion}

In this study, we explored the bi-directional relationships between total and abdominal obesity and NAFLD using MR. We found that total and abdominal obesity were causally linked to NAFLD while NAFLD was not causally linked to obesity. Results of our multivariable MR analysis suggest that waist circumference is causally linked to NAFLD regardless of body weight, while BMI is not causally linked with NAFLD once waist circumference is taken into account. Observational studies have documented similar associations (Jarvis et al., 2020). Liu et al. used bidirectional MR to explore the relationship between NAFLD, obesity, T2D and lipid traits (Liu et al., 2020). They found that both obesity and abdominal obesity had a causal effect on NAFLD. Our study provides additional support for a causal effect of abdominal obesity on NAFLD using a larger study sample size for the study outcome (NAFLD). Our study is, to our knowledge, the first to report using MVMR a causal association between abdominal obesity and NAFLD that is independent of body weight.

Having established a causal role of abdominal obesity on NAFLD and given the results of previous studies linking NAFLD to cardiometabolic diseases such as T2D and CAD, we explored whether NAFLD lies in the causal pathway linking abdominal obesity to T2D and CAD. In their MR investigation, Liu et al. also showed that NAFLD had a causal effect on T2D (OR: 1.3, 95\% CI: 1.2, 1.4, p=8.3e-14) (Liu et al., 2020). They used 2 genetic instruments for NAFLD, making it impossible to perform robust MR analyses. In our analysis, NAFLD was similarly associated with T2D and robust MR analysis were consistent with a causal association. The association was slightly decreased when we accounted for abdominal obesity using MVMR, suggesting that part of the effect of NAFLD on T2D could be attributable to pleiotropic variants shared with abdominal fat accumulation. On the other hand, the point estimate of WC on T2D also only slightly decreased when we accounted for NAFLD, suggesting that the effect of WC on T2D is minimally mediated by NAFLD. Using MVMR, our results support, for the first time to our knowledge, that the association between abdominal obesity and T2D is independent of NAFLD. We also showed that the association between abdominal obesity and CAD is independent of NAFLD. 
medRxiv preprint doi: https://doi.org/10.1101/2021.09.28.21264201; this version posted September 29, 2021. The copyright holder for this

preprint (which was not certified by peer review) is the author/funder, who has granted medRxiv a license to display the preprint in perpetuity.

Pelletier et al.

It is made available under a CC-BY 4.0 International license .

The inability of subcutaneous fat to expand by hyperplasia may partly explain why visceral fat accumulation occurs in genetically predisposed individuals (Tchernof \& Després, 2013). These excess lipids are then stored in lean tissues such as the liver, heart and skeletal muscle promoting insulin resistance (Ross et al., 2020; Ye, Richard, Gévry, Tchernof, \& Carpentier, 2021). The mechanisms by which visceral fat contributes to NAFLD may also possibly be explained by the "portal vein theory"(Rytka, Wueest, Schoenle, \& Konrad, 2011). Visceral fat is mostly drained by the portal vein, which delivers its content to the liver and exposes it to high concentrations of free fatty acids and adipokines. These have been hypothesized to lead to metabolic changes in the liver which would ultimately lead to an increased production of VLDL particles, glucose and inflammatory mediators as well as decreased insulin extraction, potentially leading to T2D and atherosclerosis.

From a clinical perspective, results of this study support the idea that previously reported associations between an elevated BMI and NAFLD may be explained by preferential abdominal fat accumulation reflected by higher waist circumference. Indeed, a significant number of individuals with elevated BMI have excess visceral fat increasing their risk of NAFLD (Liu et al., 2020; Loomis et al., 2016; Miyake et al., 2013; Wang, Guo, \& Lu, 2016). Our results also underline the limitations of the sole use of BMI in clinical practice to assess the risk associated with obesity/ectopic fat distribution. The failure of BMI to capture cardiometabolic risk had already been suggested by observation and MR studies (Nazare et al., 2015; Ross et al., 2020; Snijder, van Dam, Visser, \& Seidell, 2006). Our study adds evidence supporting waist circumference as a simple tool to assess obesity-related health hazards.

These results should encourage clinical interventions focused on visceral fat reduction, not only overall body weight reduction, to prevent cardiometabolic diseases such as NAFLD, T2D and CAD. Visceral fat can be targeted with physical activity and dietary interventions even in the absence of weight loss. A weight loss of about 5\% can result in a 15-25\% visceral fat reduction (I. J. Neeland et al., 2019). The Mediterranean diet as well as diets lower in fat and/or carbohydrate may be effective ways of reducing visceral fat, especially in physically active individuals (Gepner et al., 2018; Ross et al., 2020; Verheggen et al., 2016). There is also evidence that thiazolidinediones (TZDs) such as pioglitazone and rosiglitazone, used in the treatment of T2D, increase subcutaneous adipocytes' storage capacity and lower T2D risk (Unger, 2008). Results of the VICTORY trial, a study aimed at assessing the safety and efficiency of rosiglitazone on saphenous vein graft atherosclerosis and the cardiometabolic risk profile, 
medRxiv preprint doi: https://doi.org/10.1101/2021.09.28.21264201; this version posted September 29, 2021. The copyright holder for this

preprint (which was not certified by peer review) is the author/funder, who has granted medRxiv a license to display the preprint in perpetuity.

Pelletier et al.

It is made available under a CC-BY 4.0 International license .

showed that rosiglitazone treatment induced a $3 \mathrm{~kg}$ weight gain over 12 months and no change in visceral adiposity (Bertrand et al., 2010). Pioglitazone has also been shown to reduce hepatic steatosis and inflammation in patients with NASH (Sanyal et al., 2010) thereby providing randomized clinical trial support to our MR findings. Semaglutide, a glucagon-like protein-1 (GLP-1) receptor agonist, has recently been shown to increase the rate of NASH resolution compared with placebo (Newsome et al., 2020). A recent study on another GLP-1 receptor agonist liraglutide also recently provided evidence that this class of drug may induce a preferential loss in visceral adipose tissue (Ian J. Neeland et al.).

An important strength of the current study is the use of the largest NAFLD dataset available to date. Additionally, the use of a MVMR design that is not subject to confounding factors and reverse causality bias enables the estimation of the direct effect of closely related risk factors on cardiometabolic outcomes. Our study, however, has limitations. Few genome wide significant NAFLD SNPs were uncovered even though the largest GWAS was used. This could introduce winner's curse bias mainly for SNPs close to the genome-wide significance p-value threshold. The winners' curse may decrease the robustness of these genetic instruments and could bias the effect of NAFLD on cardiometabolic traits toward the null. However, the low number of genome-wide genetic instruments should have little impact on the analysis using NAFLD as an outcome. Nonetheless, it warrants the development of more powerful NAFLD GWAS. A second limitation is that NAFLD was not associated with T2D and CAD in univariable analyses. Although this might contradict the results of observational analyses (Fabbrini et al., 2009; Kotronen \& Yki-Järvinen, 2008; Ndumele et al., 2011), caution is needed as some SNPs that were included in these analyses are associated with NAFLD but also with lower LDL cholesterol levels. However, this type of pleiotropy does not influence our observation that genetically predicted waist circumference is associated with T2D and CAD independently of NAFLD.

In conclusion, results of this MVMR investigation suggest that independently of BMI, waist circumference is a strong and causal contributor to NAFLD. Also, the association between waist circumference and T2D and CAD is independent of NAFLD. Altogether, the results put forth that subcutaneous adipose tissue dysfunction and visceral fat accumulation may represent a root cause of a broad range of cardiometabolic diseases. Interventions targeting ectopic lipid deposition may be the key to the treatment of cardiometabolic diseases such as NAFLD, CAD and T2D. 
medRxiv preprint doi: https://doi.org/10.1101/2021.09.28.21264201; this version posted September 29, 2021. The copyright holder for this preprint (which was not certified by peer review) is the author/funder, who has granted medRxiv a license to display the preprint in perpetuity.

\section{Methods}

\section{Study populations}

We combined information from publicly accessible GWAS summary statistics of European ancestry in a two-sample MR setting. BMI and waist circumference: The summary statistics for BMI and waist circumference were obtained from the UK Biobank from 461,460 and 462,166 individuals respectively. Measures from the GIANT consortium were also included. Summary statistics for BMI were obtained from a meta-analysis of up to 125 GWAS for 339,224 European individuals (Locke et al., 2015). Summary statistics for WC were obtained from a meta-analysis of 232,101 individuals (Shungin et al., 2015). WHR adjustedfor BMI. WHR adjustedfor BMI was calculated as the ratio of waist and hip circumferences adjusted for BMI in 210,088 individuals from the GIANT consortium (Shungin et al., 2015). Non-alcoholic fatty liver disease: Genetic association estimates for a clinical diagnosis of NAFLD were obtained from a recently preprinted GWAS (8434 cases and 770,180 controls) of European ancestry from four cohorts (Ghodsian, 2021). Briefly, we performed a fixed effect GWAS meta-analysis of The Electronic Medical Records and Genomics (eMERGE) (Namjou et al., 2019) network, the UK Biobank, the Estonian Biobank and FinnGen using the METAL package (Willer, Li, \& Abecasis, 2010). NAFLD was defined by the use of electronic health record codes or hospital records. Logistic regression analysis was performed with adjustment for age,sex, BMI, genotyping site and the first three ancestries based principal components. Coronary artery disease. GWAS summary statistics for CAD were obtained from a GWAS on 122,733 cases and 424,528 controls from CARDIoGRAMplusC4D and UK Biobank (van der Harst \& Verweij, 2018). Samples from CARDIoGRAMplusC4D were drawn from a mixed population (Europeans, East Asian, South Asian, Hispanic and African American), with the majority (77\%) of the participants from European ancestry. Case status was defined by CAD diagnosis, including myocardial infarction, acute coronary syndrome,chronic stable angina or coronary stenosis. Type 2 diabetes. GWAS summary statistics for type 2 diabetes were obtained from the DIAbetes Genetics Replication and Meta-analysis (DIAGRAM) consortium and UK Biobank (74,124 cases/824,006 controls) (Mahajan et al., 2018). Case status was defined by a clinical diagnostic of T2D. 
medRxiv preprint doi: https://doi.org/10.1101/2021.09.28.21264201; this version posted September 29, 2021. The copyright holder for this

preprint (which was not certified by peer review) is the author/funder, who has granted medRxiv a license to display the preprint in perpetuity.

It is made available under a CC-BY 4.0 International license .

Pelletier et al.

Page 10

\section{$\underline{\text { Selection of genetic variants and variants harmonization }}$}

For univariable MR analysis, we selected all genome-wide significant SNPs (p-value <5e-8). We then ensured the independence of genetic instruments by clumping all neighbouring SNPs in a 10 $\mathrm{Mb}$ window with a linkage disequilibrium R2 $<0.001$ using the European 1000-genome LD reference panel. For multivariable MR analyses, we first extracted all genetic instruments that were previously selected for univariable MR analysis. We then pooled these SNPs to the lowest p-value corresponding to any of the exposures, using the same parameter setting as the univariable MR ( $R 2=0.001$ window=10 Mb). When NAFLD was used as an exposure in MVMR, we pooled the combined list of SNPs by selecting the SNP with the lowest p- value for NALFD. This procedure was implemented to select a maximum number of strong genetic instrument, as fewer genetic instruments are available for NAFLD exposure. SNPs in a $2 \mathrm{Mb}$ window of the $H L A, A B O$ and $A P O E$ genetic regions were excluded due to their complex genetic architecture. Harmonization was performed by aligning the effect sizes of different studies on the same effect allele. Palindromic SNPs with a minor allele frequency $>0.3$ were removed, otherwise we inferred positive strand alleles with effect allele frequencies. When a particular SNP was not present in the outcome datasets, we used a proxy SNPs (R2> 0.8). We used the LDlinkR V.1.1.2 package (Myers, Chanock, \& Machiela, 2020) to interrogate the LDlink API (Machiela \& Chanock, 2015) and obtain linkage disequilibrium matrix of European samples from the 1000 Genomes Project.

\section{$\underline{\text { Statistical analyses }}$}

For univariable primary MR analysis, we performed the inverse-variance weighted (IVW) method with multiplicative random effects with a standard error correction for under dispersion (Burgess, Foley, \& Zuber, 2018). MR estimates bias occurs if the genetic instruments influence several traits on different causal pathways. This phenomenon, referred to as horizontal pleiotropy, can be balanced by using multiple genetic variants combined with robust MR methods (Slob \& Burgess, 2020). To verify if pleiotropy likely influenced the primary MR results, we performed 5 different robust MR analyses: the MR- Robust Adjusted Profile Score (MR-RAPS) (Zhao, Wang, Bowden, \& Small, 2018), the contamination mixture (Slob \& Burgess, 2020), the weighted median, the weighted mode and the MR-PRESSO (Verbanck, Chen, Neale, \& Do, 2018), each making a different assumption about the 
medRxiv preprint doi: https://doi.org/10.1101/2021.09.28.21264201; this version posted September 29, 2021. The copyright holder for this preprint (which was not certified by peer review) is the author/funder, who has granted medRxiv a license to display the preprint in perpetuity.

Pelletier et al.

It is made available under a CC-BY 4.0 International license .

underlying nature of the pleiotropy. Consistent estimates across methods provides further confirmation about the nature of the causal links. All continuous exposure estimates were normalized and reported on a standard deviation scale. For dichotomous traits (i.e., diseased status GWAS on NAFLD, T2D and CAD), odds ratios were reported. For multivariable MR analysis, we conducted the IVW method (Gormley et al., 2020). The use of multivariable MR is analogous to the inclusion of measured covariates in a multivariate linear regression. Multivariable MR uses a set of overlapping genetic instrument to estimate the direct effect of an exposure on an outcome. Multivariable MRIVW analyses were performed using the MendelianRandomization V.0.5.1 package (Yavorska \& Burgess, 2017).

\section{Data and code availability}

GWAS summary statistics for anthropometric traits from GIANT are available at: https://portals.broadinstitute.org/collaboration/giant/index.php/GIANT_consortium_data_files GWAS summary statistics for BMI from UKB are available via the MR Base GWAS catalogue at id "ukb-b-19953".

GWAS summary statistics for WC from UKB are available via the MR Base GWAS catalogue at id "ukb-b-9405".

GWAS summary statistics for T2D are available at: http://diagramconsortium.org/downloads.html GWAS summary statistics for CAD are available at: https://www.cardiomics.net/download-data

The TwoSampleMR package is available at: https://github.com/MRCIEU/TwoSampleMR

The MendelianRandomization package is available at:

https://github.com/cran/MendelianRandomization

The data.table package is available at https://github.com/Rdatatable/data.table

The tidyverse package collection is available at: https://github.com/tidyverse/tidyverse

The LDlinkR package is available at: https://github.com/CBIIT/LDlinkR. 


\section{References}

Bertrand, O. F., Poirier, P., Rodés-Cabau, J., Rinfret, S., Title, L. M., Dzavik, V., . . Després, J. P. (2010). Cardiometabolic effects of rosiglitazone in patients with type 2 diabetes and coronary artery bypass grafts: A randomized placebo-controlled clinical trial. Atherosclerosis, 211(2), 565-573. doi:10.1016/j.atherosclerosis.2010.06.005

Burgess, S., Foley, C. N., \& Zuber, V. (2018). Inferring Causal Relationships Between Risk Factors and Outcomes from Genome-Wide Association Study Data. Annu Rev Genomics Hum Genet, 19, 303-327. doi:10.1146/annurev-genom-083117-021731

Chalasani, N., Younossi, Z., Lavine, J. E., Charlton, M., Cusi, K., Rinella, M., . . Sanyal, A. J. (2018). The diagnosis and management of nonalcoholic fatty liver disease: Practice guidance from the American Association for the Study of Liver Diseases. Hepatology, 67(1), 328-357. doi:10.1002/hep.29367

Charlton, M. R., Burns, J. M., Pedersen, R. A., Watt, K. D., Heimbach, J. K., \& Dierkhising, R. A. (2011). Frequency and outcomes of liver transplantation for nonalcoholic steatohepatitis in the United States. Gastroenterology, 141(4), 1249-1253. doi:10.1053/j.gastro.2011.06.061

Emdin, C. A., Khera, A. V., Natarajan, P., Klarin, D., Zekavat, S. M., Hsiao, A. J., \& Kathiresan, S. (2017). Genetic Association of Waist-to-Hip Ratio With Cardiometabolic Traits, Type 2 Diabetes, and Coronary Heart Disease. Jama, 317(6), 626-634. doi:10.1001/jama.2016.21042

Fabbrini, E., Magkos, F., Mohammed, B. S., Pietka, T., Abumrad, N. A., Patterson, B. W., . . Klein, S. (2009). Intrahepatic fat, not visceral fat, is linked with metabolic complications of obesity. Proc Natl Acad Sci U $S$ A, 106(36), 15430-15435. doi:10.1073/pnas.0904944106

Gepner, Y., Shelef, I., Schwarzfuchs, D., Zelicha, H., Tene, L., Yaskolka Meir, A., . . Shai, I. (2018). Effect of Distinct Lifestyle Interventions on Mobilization of Fat Storage Pools: CENTRAL Magnetic Resonance Imaging Randomized Controlled Trial. Circulation, 137(11), 1143-1157. doi:10.1161/circulationaha.117.030501

Ghodsian, N. A., E.; Emdin, CA.; Gobeil, E.; Taba, N.; Haas, ME.; Perrot, N.; Manikpurage, HD.; Gagnon, E.; Bourgault, J.; St-Amand, A.; Couture, C.; Mitchell, PL.; Bossé, Y.; Mathieu, P.; Vohl, MC.; Tchernof, A.;Thériault, S.; Khera, AV.;Esko, T.; Arsenault, B. (2021). Electronic Health Record-Based GenomeWide Meta-Analysis Provides New Insights on the Genetic Architecture of Non-Alcoholic Fatty Liver Disease. Cell Press Community. doi:https://dx.doi.org/10.2139/ssrn.3865274

Gormley, M., Dudding, T., Sanderson, E., Martin, R. M., Thomas, S., Tyrrell, J., . . Richmond, R. C. (2020). A multivariable Mendelian randomization analysis investigating smoking and alcohol consumption in oral and oropharyngeal cancer. Nature Communications, 11(1), 6071. Retrieved from https://doi.org/10.1038/s41467-020-19822-6. doi:10.1038/s41467-020-19822-6

Jarvis, H., Craig, D., Barker, R., Spiers, G., Stow, D., Anstee, Q. M., \& Hanratty, B. (2020). Metabolic risk factors and incident advanced liver disease in non-alcoholic fatty liver disease (NAFLD): A systematic review and meta-analysis of population-based observational studies. PLoS Med, 17(4), e1003100. doi:10.1371/journal.pmed.1003100

Kotronen, A., \& Yki-Järvinen, H. (2008). Fatty liver: a novel component of the metabolic syndrome. Arterioscler Thromb Vasc Biol, 28(1), 27-38. doi:10.1161/atvbaha.107.147538

Liu, Z., Zhang, Y., Graham, S., Wang, X., Cai, D., Huang, M., . . Liu, W. (2020). Causal relationships between NAFLD, T2D and obesity have implications for disease subphenotyping. J Hepatol, 73(2), 263-276. doi:10.1016/j.jhep.2020.03.006

Locke, A. E., Kahali, B., Berndt, S. I., Justice, A. E., Pers, T. H., Day, F. R., . . Speliotes, E. K. (2015). Genetic studies of body mass index yield new insights for obesity biology. Nature, 518(7538), 197-206. doi:10.1038/nature14177

Loomis, A. K., Kabadi, S., Preiss, D., Hyde, C., Bonato, V., St. Louis, M., . . Sattar, N. (2016). Body Mass Index and Risk of Nonalcoholic Fatty Liver Disease: Two Electronic Health Record Prospective Studies. The Journal of Clinical Endocrinology \& Metabolism, 101(3), 945-952. Retrieved from 
medRxiv preprint doi: https://doi.org/10.1101/2021.09.28.21264201; this version posted September 29, 2021. The copyright holder for this

preprint (which was not certified by peer review) is the author/funder, who has granted medRxiv a license to display the preprint in perpetuity.

It is made available under a CC-BY 4.0 International license.

Pelletier et al.

Page 13

https://doi.org/10.1210/jc.2015-3444. doi:10.1210/jc.2015-3444

Machiela, M. J., \& Chanock, S. J. (2015). LDlink: a web-based application for exploring population-specific haplotype structure and linking correlated alleles of possible functional variants. Bioinformatics, 31(21), 3555-3557. doi:10.1093/bioinformatics/btv402

Mahajan, A., Taliun, D., Thurner, M., Robertson, N. R., Torres, J. M., Rayner, N. W., . . McCarthy, M. I. (2018). Fine-mapping type 2 diabetes loci to single-variant resolution using high-density imputation and isletspecific epigenome maps. Nature Genetics, 50(11), 1505-1513. Retrieved from https://doi.org/10.1038/s41588-018-0241-6. doi:10.1038/s41588-018-0241-6

Miyake, T., Kumagi, T., Hirooka, M., Furukawa, S., Koizumi, M., Tokumoto, Y., . . Onji, M. (2013). Body mass index is the most useful predictive factor for the onset of nonalcoholic fatty liver disease: a communitybased retrospective longitudinal cohort study. Journal of Gastroenterology, 48(3), 413-422. Retrieved from https://doi.org/10.1007/s00535-012-0650-8. doi:10.1007/s00535-012-0650-8

Myers, T. A., Chanock, S. J., \& Machiela, M. J. (2020). LDlinkR: An R Package for Rapidly Calculating Linkage Disequilibrium Statistics in Diverse Populations. Frontiers in Genetics, 11(157). Retrieved from https://www.frontiersin.org/article/10.3389/fgene.2020.00157. doi:10.3389/fgene.2020.00157

Namjou, B., Lingren, T., Huang, Y., Parameswaran, S., Cobb, B. L., Stanaway, I. B., . . Harley, J. B. (2019). GWAS and enrichment analyses of non-alcoholic fatty liver disease identify new trait-associated genes and pathways across eMERGE Network. BMC Med, 17(1), 135. doi:10.1186/s12916-019-1364-z

Nazare, J. A., Smith, J., Borel, A. L., Aschner, P., Barter, P., Van Gaal, L., . . Després, J. P. (2015). Usefulness of measuring both body mass index and waist circumference for the estimation of visceral adiposity and related cardiometabolic risk profile (from the INSPIRE ME IAA study). Am J Cardiol, 115(3), 307-315. doi:10.1016/j.amjcard.2014.10.039

Ndumele, C. E., Nasir, K., Conceiçao, R. D., Carvalho, J. A., Blumenthal, R. S., \& Santos, R. D. (2011). Hepatic steatosis, obesity, and the metabolic syndrome are independently and additively associated with increased systemic inflammation. Arterioscler Thromb Vasc Biol, 31(8), 1927-1932.

doi:10.1161/atvbaha.111.228262

Neeland, I. J., Marso, S. P., Ayers, C. R., Lewis, B., Oslica, R., Francis, W., . . Joshi, P. H. Effects of liraglutide on visceral and ectopic fat in adults with overweight and obesity at high cardiovascular risk: a randomised, double-blind, placebo-controlled, clinical trial. The Lancet Diabetes \& Endocrinology. Retrieved from https://doi.org/10.1016/S2213-8587(21)00179-0. doi:10.1016/S2213-8587(21)00179-0

Neeland, I. J., Ross, R., Després, J. P., Matsuzawa, Y., Yamashita, S., Shai, I., . . Eckel, R. H. (2019). Visceral and ectopic fat, atherosclerosis, and cardiometabolic disease: a position statement. Lancet Diabetes Endocrinol, 7(9), 715-725. doi:10.1016/s2213-8587(19)30084-1

Newsome, P. N., Buchholtz, K., Cusi, K., Linder, M., Okanoue, T., Ratziu, V., . . Harrison, S. A. (2020). A Placebo-Controlled Trial of Subcutaneous Semaglutide in Nonalcoholic Steatohepatitis. New England Journal of Medicine, 384(12), 1113-1124. Retrieved from https://www.nejm.org/doi/full/10.1056/NEJMoa2028395. doi:10.1056/NEJMoa2028395

Ross, R., Neeland, I. J., Yamashita, S., Shai, I., Seidell, J., Magni, P., . . Després, J. P. (2020). Waist circumference as a vital sign in clinical practice: a Consensus Statement from the IAS and ICCR Working Group on Visceral Obesity. Nat Rev Endocrinol, 16(3), 177-189. doi:10.1038/s41574-019-0310-7

Rytka, J. M., Wueest, S., Schoenle, E. J., \& Konrad, D. (2011). The portal theory supported by venous drainageselective fat transplantation. Diabetes, 60(1), 56-63. Retrieved from

https://pubmed.ncbi.nlm.nih.gov/20956499

https://www.ncbi.nlm.nih.gov/pmc/articles/PMC3012197/. doi:10.2337/db10-0697

Sanderson, E., Davey Smith, G., Windmeijer, F., \& Bowden, J. (2019). An examination of multivariable Mendelian randomization in the single-sample and two-sample summary data settings. Int J Epidemiol, 48(3), 713-727. doi:10.1093/ije/dyy262

Sanyal, A., Chalasani, N., Kowdley, K., McCullough, A., Diehl, A., Bass, N., . . Robuck, P. (2010). Pioglitazone, Vitamin E, or Placebo for Nonalcoholic Steatohepatitis. The New England journal of medicine, 362, 1675-1685. doi:10.1056/NEJMoa0907929

Shungin, D., Winkler, T. W., Croteau-Chonka, D. C., Ferreira, T., Locke, A. E., Mägi, R., .. Mohlke, K. L. 
medRxiv preprint doi: https://doi.org/10.1101/2021.09.28.21264201; this version posted September 29, 2021. The copyright holder for this

preprint (which was not certified by peer review) is the author/funder, who has granted medRxiv a license to display the preprint in perpetuity.

It is made available under a CC-BY 4.0 International license .

Pelletier et al.

Page 14

(2015). New genetic loci link adipose and insulin biology to body fat distribution. Nature, 518(7538), 187-196. doi:10.1038/nature14132

Slob, E. A. W., \& Burgess, S. (2020). A comparison of robust Mendelian randomization methods using summary data. Genet Epidemiol, 44(4), 313-329. doi:10.1002/gepi.22295

Snijder, M. B., van Dam, R. M., Visser, M., \& Seidell, J. C. (2006). What aspects of body fat are particularly hazardous and how do we measure them? Int J Epidemiol, 35(1), 83-92. doi:10.1093/ije/dyi253

Tchernof, A., \& Després, J. P. (2013). Pathophysiology of human visceral obesity: an update. Physiol Rev, 93(1), 359-404. doi:10.1152/physrev.00033.2011

Tilg, H., Moschen, A. R., \& Roden, M. (2017). NAFLD and diabetes mellitus. Nat Rev Gastroenterol Hepatol, 14(1), 32-42. doi:10.1038/nrgastro.2016.147

Unger, R. H. (2008). Reinventing type 2 diabetes: pathogenesis, treatment, and prevention. Jama, 299(10), 11851187. doi:10.1001/jama.299.10.1185

van der Harst, P., \& Verweij, N. (2018). Identification of 64 Novel Genetic Loci Provides an Expanded View on the Genetic Architecture of Coronary Artery Disease. Circ Res, 122(3), 433-443. doi:10.1161/circresaha.117.312086

Verbanck, M., Chen, C. Y., Neale, B., \& Do, R. (2018). Detection of widespread horizontal pleiotropy in causal relationships inferred from Mendelian randomization between complex traits and diseases. Nat Genet, 50(5), 693-698. doi:10.1038/s41588-018-0099-7

Verheggen, R. J., Maessen, M. F., Green, D. J., Hermus, A. R., Hopman, M. T., \& Thijssen, D. H. (2016). A systematic review and meta-analysis on the effects of exercise training versus hypocaloric diet: distinct effects on body weight and visceral adipose tissue. Obes Rev, 17(8), 664-690. doi:10.1111/obr.12406

Wang, L., Guo, J., \& Lu, J. (2016). Risk factor compositions of nonalcoholic fatty liver disease change with body mass index in males and females. Oncotarget, 7(24), 35632-35642. doi:10.18632/oncotarget.9691

Welsh, P., Polisecki, E., Robertson, M., Jahn, S., Buckley, B. M., de Craen, A. J., . . Sattar, N. (2010). Unraveling the directional link between adiposity and inflammation: a bidirectional Mendelian randomization approach. J Clin Endocrinol Metab, 95(1), 93-99. doi:10.1210/jc.2009-1064

Willer, C. J., Li, Y., \& Abecasis, G. R. (2010). METAL: fast and efficient meta-analysis of genomewide association scans. Bioinformatics, 26(17), 2190-2191. doi:10.1093/bioinformatics/btq340

Yavorska, O. O., \& Burgess, S. (2017). MendelianRandomization: an R package for performing Mendelian randomization analyses using summarized data. Int J Epidemiol, 46(6), 1734-1739. doi:10.1093/ije/dyx034

Ye, R. Z., Richard, G., Gévry, N., Tchernof, A., \& Carpentier, A. C. (2021). Fat Cell Size: Measurement Methods, Pathophysiological Origins, and Relationships with Metabolic Dysregulations. Endocr Rev. doi:10.1210/endrev/bnab018

Younossi, Z. M., Koenig, A. B., Abdelatif, D., Fazel, Y., Henry, L., \& Wymer, M. (2016). Global epidemiology of nonalcoholic fatty liver disease-Meta-analytic assessment of prevalence, incidence, and outcomes. Hepatology, 64(1), 73-84. doi:10.1002/hep.28431

Zhao, Q., Wang, J., Bowden, J., \& Small, D. (2018). Statistical inference in two-sample summary-data Mendelian randomization using robust adjusted profile score. Annals of Statistics, 48. doi:10.1214/19-AOS1866 
medRxiv preprint doi: https://doi.org/10.1101/2021.09.28.21264201; this version posted September 29, 2021. The copyright holder for this preprint (which was not certified by peer review) is the author/funder, who has granted medRxiv a license to display the preprint in perpetuity.

\section{Pelletier et al.}

It is made available under a CC-BY 4.0 International license .

Page 15

\section{Acknowledgements}

We would like to thank all study participants as well as all investigators of the studies that were used throughout the course of this investigation. WP holds a masters research award from the Canadian Institutes of Health Research (CIHR). EG and IMP hold a doctoral research award from the Fonds derecherche du Québec: Santé. (FRQS). BJA and ST hold junior scholar awards from the FRQS. MCVis Canada Research Chair in Genomics applied to Nutrition and Metabolic Health. AT is co-Director of the Research Chair in Bariatric and Metabolic Surgery at Laval University. Part of this study was supported by the European Union through the European Regional Development fund. The work of Estonian Genome Center, Univ. of Tartu has been supported by the European Regional Development Fund and grants No. GENTRANSMED (20142020.4.01.15-0012), MOBERA5 (Norface Network project no 462.16.107) and 2014- 2020.4.01.16-0125.

This study was also funded by the European Union through Horizon 2020 research and innovation programme under grant no 810,645 and through the European Regional Development Fund.

\section{Disclosures}

BJA is a consultant for Novartis and Silence Therapeutics and has received research contracts from Pfizer, Ionis Pharmaceuticals and Silence Therapeutics. AT receives research funding from Johnson \& Johnson Medical Companies, Medtronic, Bodynov and GI Windows for studies on bariatric surgery and received consulting fees from Novo Nordisk and Bausch Health. 
medRxiv preprint doi: https://doi.org/10.1101/2021.09.28.21264201; this version posted September 29, 2021. The copyright holder for this

preprint (which was not certified by peer review) is the author/funder, who has granted medRxiv a license to display the preprint in perpetuity.

It is made available under a CC-BY 4.0 International license .

Pelletier et al.

Page 16

\section{Figure legends}

Figure 1. Schematic overview of the analytical framework used to disentangle the causal relationships between abdominal obesity, non-alcoholic fatty liver disease and type 2 diabetes.

A) Design of the bi-directional associations between obesity (assessed using the body mass index and waist circumference) and non-alcoholic fatty liver disease (NAFLD) using univariable and multivariable mendelian randomization (MVMR). B) Design of the MVMR analysis investigating the respective contributions of abdominal obesity and NAFLD on type 2 diabetes and coronary artery disease.

Figure 2. Bi-directional associations between obesity and non-alcoholic fatty liver disease (NAFLD). A) association of body mass index and waist circumference (exposures) with NAFLD (outcome) using inverse-variance weighted Mendelian randomization (IVW-MR) and robust MR analyses B) association of NAFLD (exposure) with body mass index and waist circumference (outcomes) using IVW-MR and robust MR analyses.

Figure 3. Association between waist circumference and body mass index with non-alcoholic fatty liver disease using univariable and multivariable Mendelian randomization.

Figure 4. Association between waist-to-hip ratio adjusted for body mass index and non-alcoholic fatty liver disease using multiple Mendelian randomization methods.

Figure 5. Association between waist circumference and coronary artery disease and type 2 diabetes before and after accounting for non-alcoholic fatty liver disease using univariable and multivariable Mendelian randomization. 
A)

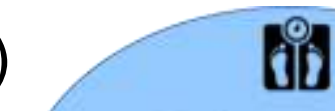

\section{Body mass index}

UK Bioank/GIANT

$\mathrm{N}=461,460 / 339,224$

European ancestries

437/68 SNPS ( $P<5 E-08)$

\section{Bidirectional MR}

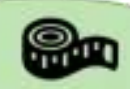

Waist circumference

UK Bioank/GIANT

$N=462,166 / 232,101$

European ancestries 354/41 SNPS $(P<5 E-08)$

B)
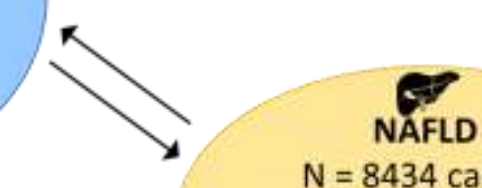

$\mathrm{N}=8434$ cases 770,180 controls

European ancestries 12 SNPS $(P<5 E-06)$

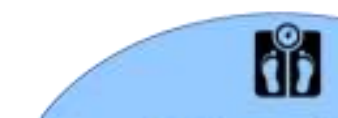

Body mass index UK Bioank/GIANT $N=461,460 / 339,224$ European ancestries 437/68 SNPs ( $P<5 E-08)$

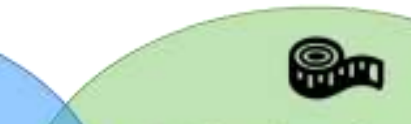

Waist circumference

UK Bioank/GIANT

$N=462,166 / 232,101$

European ancestries 354/41 SNPS ( $P<5 E-08)$

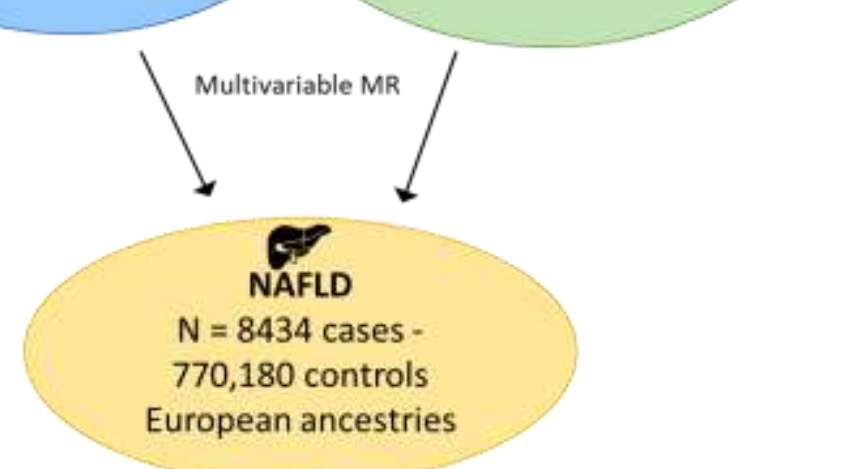

Coronary artery disease CARDIoGRAMplusC4D + UKB

Van der Harst $P$

$\mathrm{N}=122,733$ cases -

424,528 controls

European ancestries
Waist circumference UK Bioank/GIANT $\mathrm{N}=462,166 / 232,101$ European ancestries 354/41 SNPS $(P<5 E-08)$

\section{Figure 1}

European ancestries 
WC/BMI on NAFLD

n SNP

Body mass index

Primary analysis

Inverse variance weighted

Consensus methods

Weighted mode

Weighted median

Pleiotropy test

Robust adjusted profile score (RAPS)

Contamination mixture

Outlier-robust methods

MR-PRESSO (Outlier-corrected)

\section{Waist circumference}

Primary analysis

Inverse variance weighted

Consensus methods

Weighted mode

Weighted median

Pleiotropy test

Robust adjusted profile score (RAPS)

Contamination mixture

Outlier-robust methods

MR-PRESSO (Outlier-corrected)

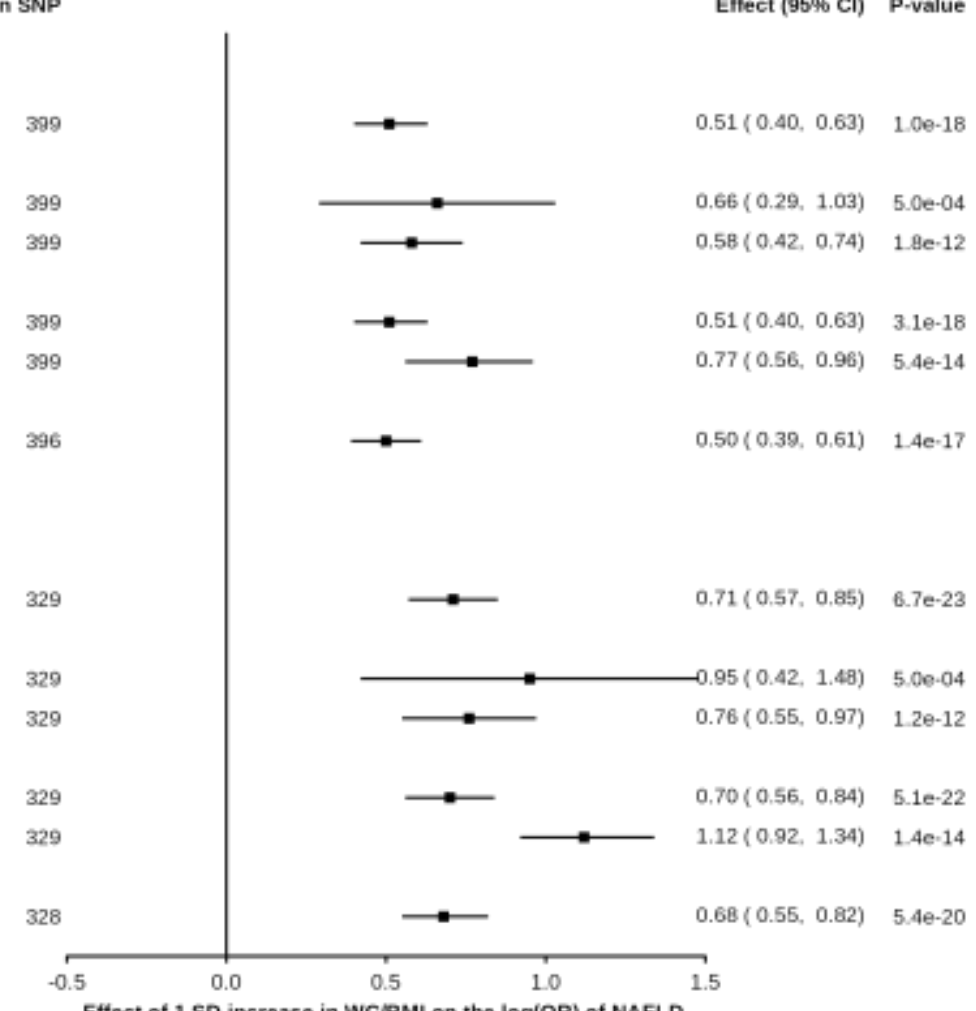

NAFLD on WCIBMI

n SNP

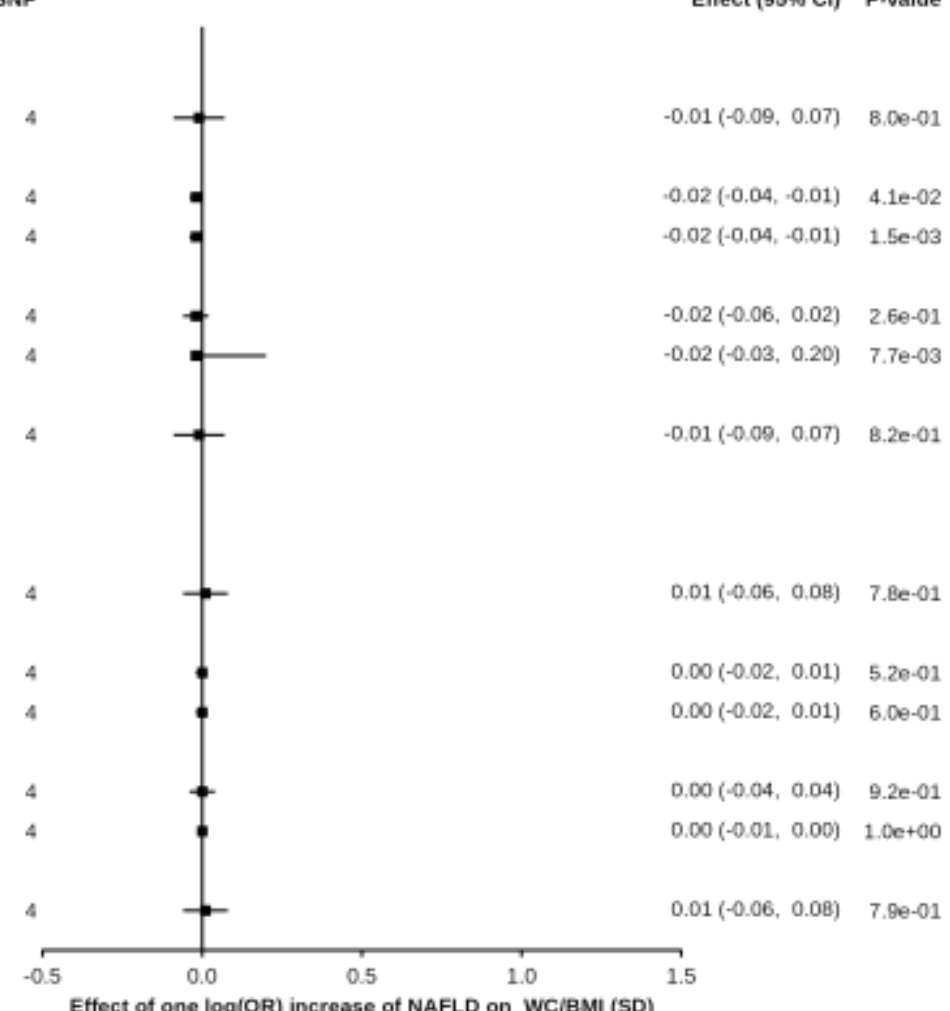

Figure 2 
n SNP

\section{Univariable}

Waist circumference

Body mass index

\section{Multivariable}

Waist circumference

Body mass index

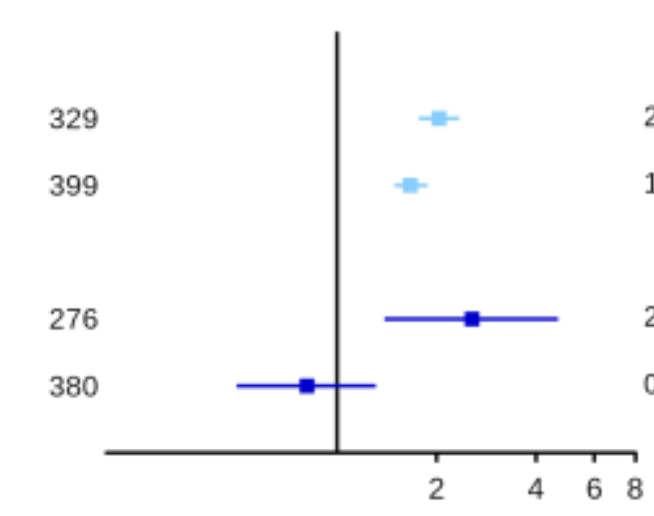

Odds Ratio of NAFLD per 1-SD higher anthropometric trait
OR $(95 \% \mathrm{Cl}) \quad$ P-value

$2.03(1.77,2.34) \quad 6.7 e-23$

$1.67(1.49,1.88) \quad 1.0 \mathrm{e}-18$

$2.56(1.39,4.66) \quad 2.4 \mathrm{e}-03$

$0.81(0.50,1.31) \quad 3.9 e-01$

\section{Figure 3}




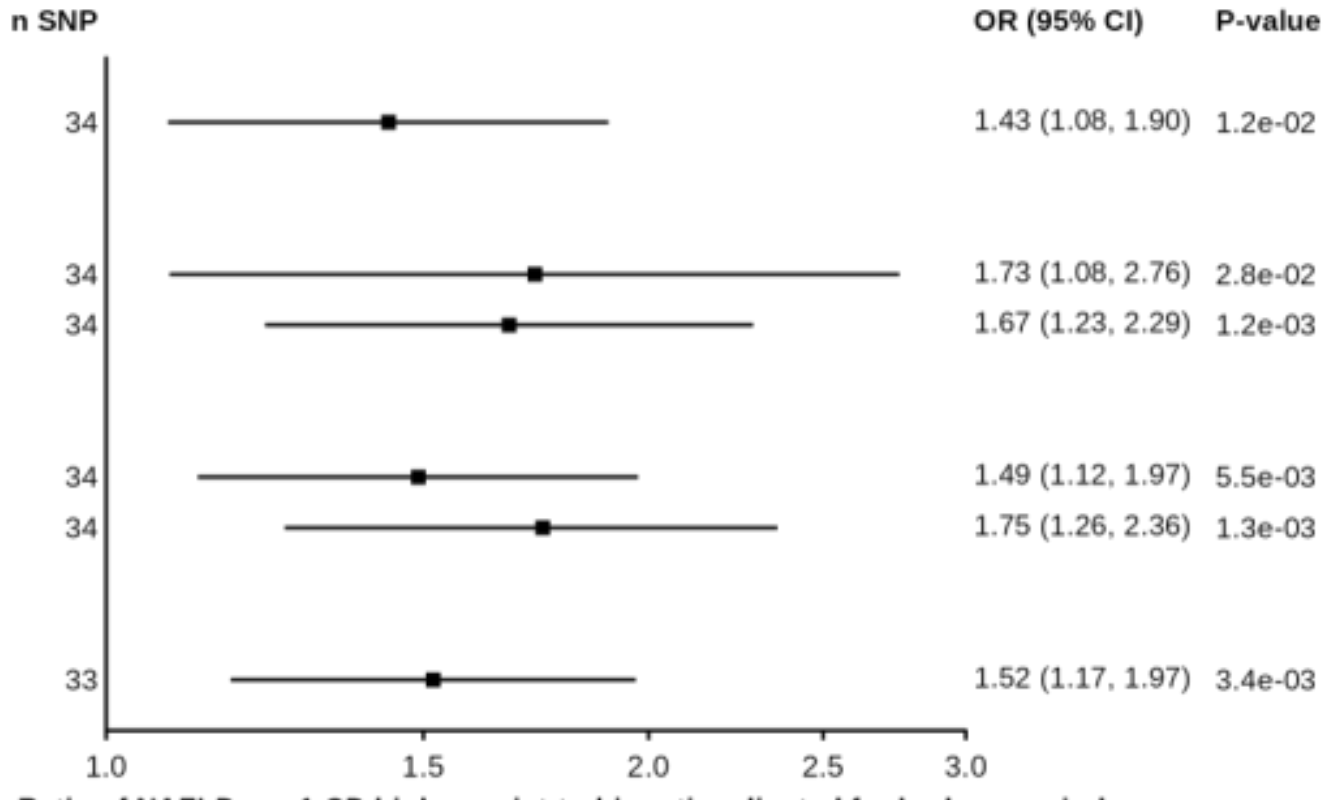

Odds Ratio of NAFLD per 1-SD higher waist-to-hip ratio adjusted for body mass index

Figure 4 
Type 2 diabetes

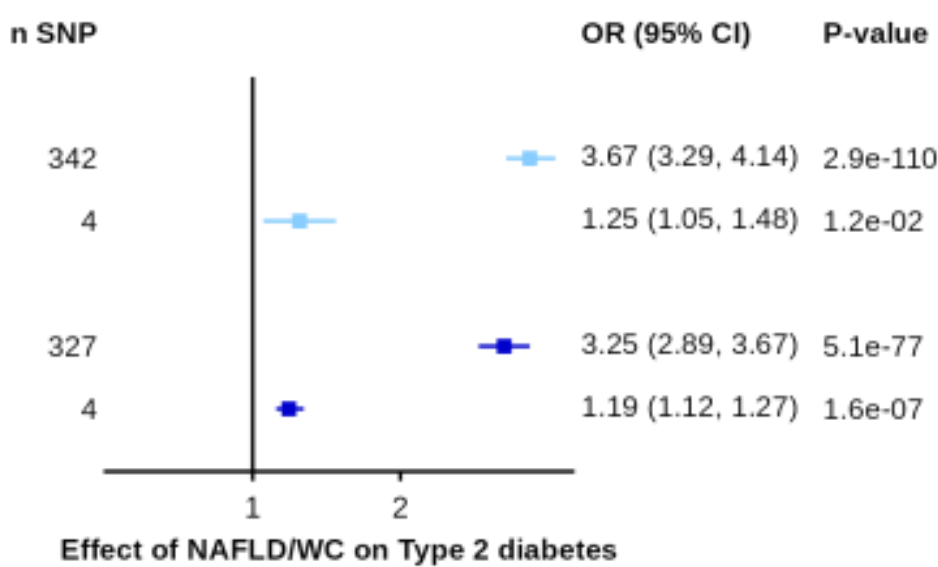

Coronary artery disease

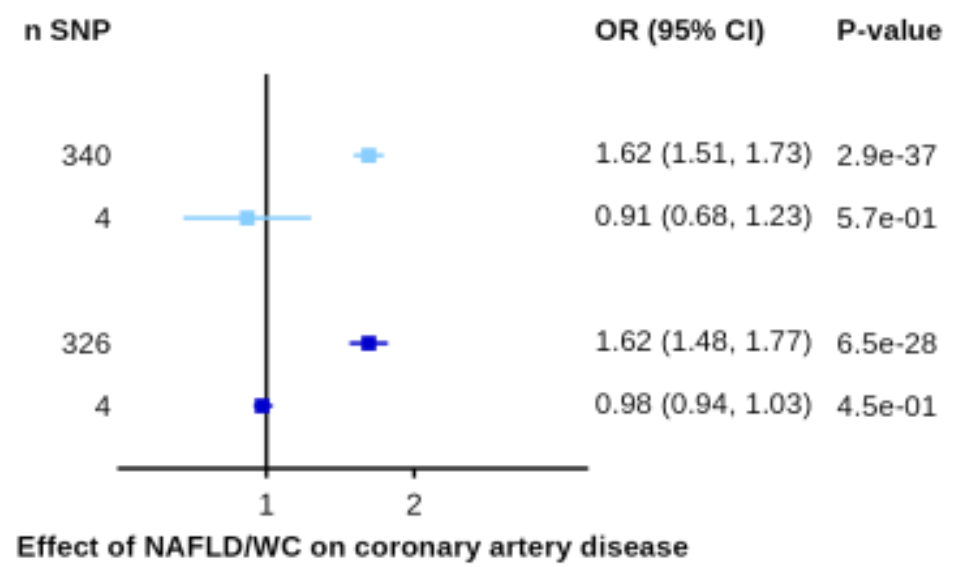

Figure 5 